\title{
A New Variety of Cold-resistant and Early Maturing Cucurbita maxima 'Jianbao'
}

\author{
Yang Chen \\ Agricultural Bio-Resources Research Institute, Fujian Academy of Agricultural \\ Sciences, Fuzhou 350003, China
}

\section{Xianzhi Zhou}

Agricultural Bio-Resources Research Institute, Fujian Academy of Agricultural Sciences, Fuzhou 350003, China; and Fuzhou Tropical Crop Scientific Observation Experimental Station of Ministry of Agriculture and Rural Affairs, Fuzhou 350003, China

\section{Yongsheng Lin and Yucan Zhang Agricultural Bio-Resources Research Institute, Fujian Academy of Agricultural Sciences, Fuzhou 350003, China}

Additional index words. crude fiber, early maturing, powdery mildew resistance, pumpkin, self-fertilization, vitamin $\mathrm{C}$

Pumpkins are one of the most important gourd vegetables in China. Their flesh is rich in nutrients, containing abundance of vitamins, minerals, and sugars (Wang, 2002). Pumpkins have the ninth largest acreage among vegetables in China, covering an area of $400,000 \mathrm{hm}^{2}$ and yielding more than 700 million tons. Furthermore, China is the world's largest producer of pumpkins (Yang et al., 2016; Zhao et al., 2009). Cucurbita moschata, Cucurbita maxima, and C. pepo are the main species in China (Chu et al., 2007). The acreage of small-sized pumpkins has been gradually increasing because of changes in the family structure. Because of its high starch content and sweet taste, more C. maxima species were introduced from abroad since the early 1990 s, and its acreage has been expanding each year. However, there is still a problem of low yield in the extensive cultivation of this species (Jia et al., 2007; Liu et al., 2008). In addition, the yield and quality of $C$. maxima fruits are susceptible to early spring frost damage, powdery mildew, and different cultivation conditions. There is still a lack of cold-resistant varieties suitable for early spring planting in the southern region. To enrich the vegetable market and develop an F1 hybrid line of high-quality $C$. maxima that meets market demands, our project group collected highquality C. maxima from Japan, India, and Taiwan and screened for a batch of excellent germplasm resources. The research setup

\footnotetext{
Received for publication 29 Mar. 2019. Accepted for publication 24 June 2019.

This research was supported by Fujian Provincial Public Welfare Research Project (2018R1017-5).

Y.C. and X.Z. are the corresponding authors. E-mail: 258269673@qq.com and xianzhizhou@, 126.com.
}

consisted of a consecutive selection of individual plants to breed a new high-quality, early maturing, high-yield variety of $C$. maxima 'Jianbao', via a selfing method.

\section{Origin}

Since 1998, 25 types of pumpkin germplasm resources (F1 hybrids) have been introduced from Japan, India, and Taiwan. After several years of serial self-fertilization and directed breeding, 28 stable inbred lines that met the breeding objectives were retained. According to market demand, in 2010, five stable inbred lines with excellent traits were selected as parent materials for an optimal combination to produce 6 hybrid combinations. Based on field comparison trials, the combination " $2 \mathrm{~B}-2-3 \times 2 \mathrm{~A}-3-4$ " (named 'Jianbao') produced fruits with dark green skin and pale green spots on dark skin that have a beautiful appearance (Fig. 1A), early maturation, high seed germination and seedling rate, easy fruit setting, high yield, good mouth feel and taste, and outstanding overall trait performance. This variety was found to be popular among farmers and consumers. In June 2016, it was approved by the Fujian Provincial Crop Variety Registration Committee (Fujian Vegetable Registration No. 2016002). At present, it has been cultivated equally across more than $100 \mathrm{hm}^{2}$ in Ningde and Nanping in Fujian Province.

$\mathrm{S}_{0}$ generation seeds of the female parent 2B-2-3 of 'Jianbao' pumpkin were obtained in the winter of 2003 through selffertilization of 'Japanese Millet Gold' kabocha (named Riben Sujin Nangua in Chinese, C. maxima, F1 hybrids). From the Spring of 2004 to the Spring of 2007, continuous selfpollination was used to obtain $\mathrm{S}_{1}-\mathrm{S}_{4}$ generation seeds, $\mathrm{S}_{5}$ generation seeds were planted in Spring 2008 and 2009, and $\mathrm{S}_{6}-\mathrm{S}_{7}$ genera- tion seeds were obtained by a mass selection method, resulting in a stable homozygous inbred line named 2B-2-3; this variety grows vigorously and has strong disease resistance, short internodes, and medium-sized leaves, with a grayish-green color. The first female flower appears at around the seventh node of the main vine. The fruit is flat and round with green skin, has a horizontal and vertical diameter of $\approx 15 \times 10 \mathrm{~cm}$, produces yellowish-brown seeds, weighs $\approx 1.0 \mathrm{~kg}$ per fruit, and has golden yellow flesh, i.e., 2.5-3 $\mathrm{cm}$ in thickness. $\mathrm{S}_{0}$ generation seeds of the male parent 2A-3-4 of 'Jianbao' pumpkin were obtained in the Winter of 2003 through self-fertilization of 'Japanese Silver World' kabocha (named Riben Yinshijie Nangua in Chinese, C. maxima, F1 hybrids); from the Spring of 2004 to the Autumn of 2007, continuous self-pollination was used to obtain $\mathrm{S}_{1}-\mathrm{S}_{4}$ generation seeds; $\mathrm{S}_{4}$ generation seeds were planted in Spring 2008 and 2009, and $\mathrm{S}_{5}-\mathrm{S}_{6}$ generation seeds were obtained by a mass selection method, resulting in a stable homozygous inbred line named 2A-3-4. This variety grows vigorously and has strong disease resistance. Its internode is slightly longer than that of the female parent, and its leaves are grayish-green with white spots. The first female flower appears at around the 13th node of the main vine. The fruit is flat and round with pale green skin, has a horizontal and vertical diameter of $14 \times 12 \mathrm{~cm}$, weighs $\approx 1.5 \mathrm{~kg}$ per fruit, produces white seed, has bright yellow flesh that is $\approx 2-2.5 \mathrm{~cm}$ in thickness, and is sweeter and softer in texture.

\section{Description and Performance}

The 'Jianbao' combination was prepared in the Spring of 2011, and the cold resistance test was conducted in 2012. Field trials were carried out in 2012 and 2013, with 'Japanese Sweet Chestnut' kabocha (C. maxima) and 'Beibei' pumpkin (C. maxima) as controls.

Germination and plug tray seedling cultivation. About 500 full and mature seeds of the three pumpkin varieties were first soaked in $55^{\circ} \mathrm{C}$ warm water for $15 \mathrm{~min}$ and then in pure water for $5 \mathrm{~h}$. The seeds were then wrapped with sterile gauze and placed in an incubator at $30{ }^{\circ} \mathrm{C}$ for germination for $\approx 48 \mathrm{~h}$. Seeds that have sprouted were placed in plug trays for seedling cultivation. The seedling substrate was purchased from Baili Seedling Co., Ltd (Xianmen, Fujian Province, China). When the seedlings reached the stage of three leaves and one terminal bud, those with robust and consistent growth were selected for the cold resistance study or field trials.

Cold resistance test. On 18 Feb. 2012, seedlings with consistent growth were transferred into an artificial climate chamber (location: Dongzhang town, Fuqing city, and Fuzhou city). Thirty plants of each variety were selected for cold treatment for $7 \mathrm{~d}$, with a daytime temperature of $12{ }^{\circ} \mathrm{C}$, nighttime temperature of $5{ }^{\circ} \mathrm{C}, 12 \mathrm{~h}$ of light at a light intensity of $3000 \mathrm{~lx}$, and humidity of $70 \%$. This procedure was repeated in 
triplicate. The seedlings were then removed for relevant measurements and recovery test at room temperature. According to the criteria set by Semeniuk et al. (1986), the seedlings were classified according to the signs of CI into 6 grades, from 0 to 5 ; 0 , no sign of damage; 1, leaves are slightly wrinkled, yellowing or slight dehydration of the first or second leaf margin, and the third leaf and terminal leaves are without damage; 2 , leaves are wrinkled, severe dehydration of the first and second leaf margins, yellowing or slight dehydration of the third leaf margin, and no obvious damage to the terminal leaves; 3 , dehydration spots in the middle of the first and second leaves, severe dehydration of the third leaf margin, and slight dehydration of the terminal leaves; 4, dehydration spots in the middle of the first and second leaves are connected into patches leading to wilting, dehydration spots in the middle of the third leaf, and obvious dehydration of the terminal leaves but can be recovered at room temperature; 5 , all leaves are severely dehydrated and wilted, and the seedlings cannot be recovered at room temperature. CI index $(\mathrm{CI})=\sum$ (number of plants per grade $\times$ grade level $) /($ total number of plants $\times$ highest grade) $\times 100 \%$.

In the Spring of 2012 and 2013, a split block design was set up for the trials, which
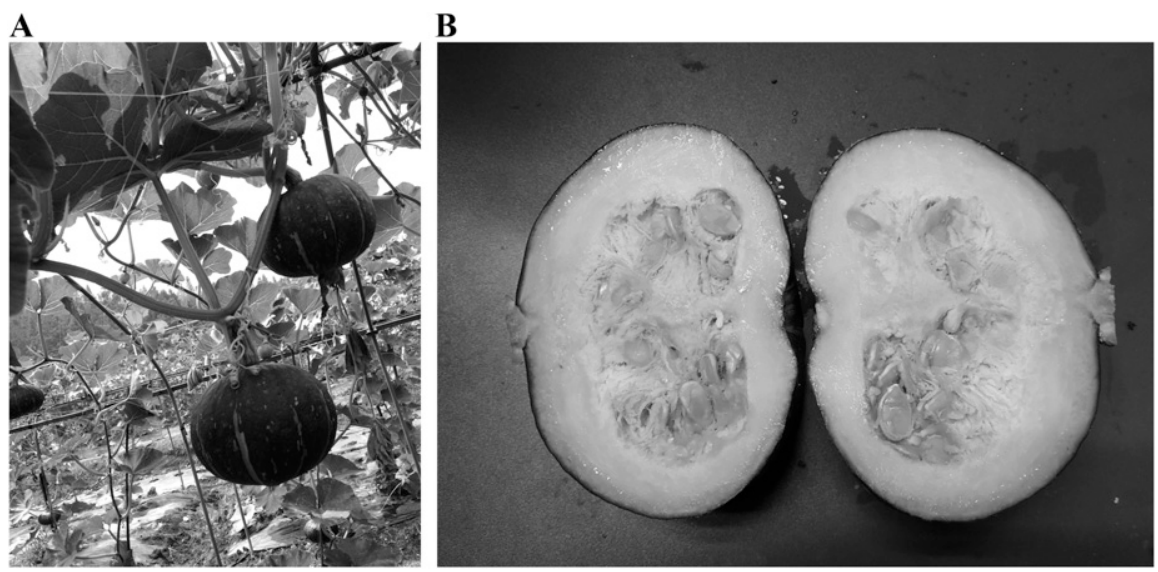

Fig. 1. (A) Hanging vine-cultivated ripe 'Jianbao'. (B) Flesh of ripe 'Jianbao'. included three cultivars with three replications across five locations over 2 years. Variety comparison trials were performed in Puyuan town and Yangzhong town, Zhouning County, Ningde city; Longjing town, Dehua County, Quanzhou city; Wuhu town, Nanping city; and Pangu township, Yongtai County, Fuzhou city in Fujian Province. All trial plots contained sandy soil. Greenhouse vine cultivation was performed in the Puyuan town of Zhouning County. The row spacing was $0.7 \times 1.6 \mathrm{~m}$ and plot area was $30.0 \mathrm{~m}^{2}$. Twenty-seven plants were planted at random in each plot with 3 replications. Open-field, A-stick trellises were performed at the other four test bases. The row spacing was $0.9 \times 1.5 \mathrm{~m}$ and plot area was $30.4 \mathrm{~m}^{2}$. Twenty-two plants were planted at random in each plot with 3 replications. In 2014-15, large-scale production trials were conducted in Fuzhou city, Ningde city, Quanzhou city, and Nanping city of Fujian Province. Base fertilizer was applied before planting at $1200 \mathrm{~kg} \cdot \mathrm{hm}^{-2}$ and another three times during the growing period at 200 $\mathrm{kg} \cdot \mathrm{hm}^{-2}$. The fertilizer used was $17 \mathrm{~N}-17 \mathrm{P}$ $17 \mathrm{~K}$ compound fertilizer (Stanley Agriculture Group Co., Ltd, Dezhou, Shandong Province, China). Watering and weeding were performed at appropriate times based on the drought levels and weed growth of the study area. Field survey was carried out $15 \mathrm{~d}$ after the occurrence of powdery mildew. The powdery mildew was classified into 10 grades, from 0 to 9 ; 0 , no symptom; 1 , disease area accounts for $5 \%$ or less of the entire leaf area; 2 , disease area more than $5 \%$ and less than or equal to $10 \% ; 3$, disease area more than $10 \%$ and less than or equal to $15 \% ; 4$, disease area more than $15 \%$ and less than or equal to $20 \%$; 5 , disease area more than $20 \%$ and less than or equal to $25 \%$; 6 , disease area more than $25 \%$ and less than or equal to $30 \%$; 7 , disease area more than $30 \%$ and less than or equal to $35 \% ; 8$, disease area more than $35 \%$ and less than or equal to $40 \%$; and 9 , disease area more than $40 \%$. Disease index $(D I)=\sum$ (number of leaves per grade $\times$ grade level)/(total number of leaves $\times$ highest grade) $\times 100 \%$ (Fang, 2001). The fruit color, shape, single fruit weight, and other biological trait data were collected after the pumpkins had matured, and yield per hectare was calculated according to the yield per plot. At the same time, 60 ripe pumpkins were randomly selected from each variety and divided into 3 groups, with 20 pumpkins in each group. Thirty $g$ of fresh flesh was obtained from each pumpkin, which gave a total of $600 \mathrm{~g}$ in each group. The flesh was dried in an oven at $65^{\circ} \mathrm{C}$ for $48 \mathrm{~h}$, then the dry weight was measured, and the dry matter content was calculated.

'Jianbao' is an early maturing variety, which is more resistant to low temperatures than 'Japanese Sweet Chestnut' kabocha (Table 1), and hence, is suitable for early spring planting in the southern region. The first female flower appeared at the fifth-10th node of the main vine. The fruit was harvested 35-40 d after setting. The fruit is flat and round (Fig. 1A) with a single fruit weight of $1.0-2.0 \mathrm{~kg}$ and dark green skin with pale green stripes (Fig. 1A). The flesh is thick, is orange-yellow in color (Fig. 1B), and has a firm and powdery texture, sweet taste, good mouth feel, and chestnut-like flavor. 'Jianbao' is moderately resistant to powdery mildew. The single fruit weight was similar to that of 'Japanese Sweet Chestnut' kabocha and heavier than 'Beibei' pumpkin $(P<$

Table 1. Measurement results of the chilling index (2012), powdery mildew resistance, fruit biological characteristics, dry weight, and yield of three Cucurbita maxima varieties (2012-13).

\begin{tabular}{|c|c|c|c|c|c|}
\hline Varieties & $\begin{array}{c}\text { Chilling } \\
\text { index }^{\mathrm{z}}(\%)\end{array}$ & $\begin{array}{c}\text { Powdery mildew } \\
\text { resistance }(\%)\end{array}$ & $\begin{array}{l}\text { Single fruit } \\
\mathrm{wt}^{\mathrm{x}}(\mathrm{kg})\end{array}$ & $\begin{array}{c}\text { Dry matter } \\
\text { content }^{\mathrm{w}}(\%)\end{array}$ & Yield $^{\mathrm{v}}\left(\mathrm{kg} \cdot \mathrm{hm}^{-2}\right)$ \\
\hline 'Japanese Sweet Chestnut' kabocha & $35.7 \pm 2.08 \mathrm{~b}$ & $65.3 \pm 4.81 \mathrm{a}$ & $1.34 \pm 0.05 \mathrm{a}$ & $13.0 \pm 0.17 \mathrm{~b}$ & $29,429.8 \pm 910.58 b$ \\
\hline
\end{tabular}

${ }^{\mathrm{z}}$ The chilling index was calculated for every 30 plants and the mean value of the triplicate was obtained. The cold resistance of seedlings was classified into three grades according to the chilling index: resistant (R): $\mathrm{CI} \leq 40 \%$, moderately resistant (MR): $40 \%<\mathrm{CI} \leq 80 \%$, and sensitive (S): $\mathrm{CI}>80 \%$. The greater the chilling index, the more serious the damage and vice versa ( $\mathrm{Li}$ and $\mathrm{Zhu}, 2005)$. Different letters within the same column indicate the difference was significant as determined by Duncan's multiple range test $(P<0.05)$.

${ }^{\mathrm{y}}$ Mean value of scores for all plants in each trial plot during the 2-year field cultivation trial. Powdery mildew resistance was divided into six grades: immunity, $\mathrm{DI}=0$; highly resistant, $0<\mathrm{DI}<20 \%$; resistant, $20 \% \leq \mathrm{DI}<40 \%$; moderately resistant, $40 \% \leq \mathrm{DI}<60 \%$; susceptible, $60 \% \leq \mathrm{DI}<80 \%$; and highly susceptible, $\mathrm{DI} \geq 80 \%$ (Fang, 2001). Different letters within the same column indicate the difference was significant $(P<0.05)$.

${ }^{\mathrm{x}}$ Mean weight of 30 fruits in each plot during the 2-year field cultivation trial. Different letters within the same column indicate the difference was significant $(P<0.05)$

${ }^{\mathrm{w}}$ Ratio of dry weight to fresh weight of fruit flesh and mean value of three groups. Different letters within the same column indicate the difference was significant $(P<0.05)$.

${ }^{v}$ Mean yield per hectare is derived from the yield of three plots for each variety during the 2-year field cultivation trial. Different letters within the same column indicate the difference was significant $(P<0.05)$. 
Table 2. Quality test results of 'Jianbao', 'Japanese Sweet Chestnut', and 'Beibei'.

\begin{tabular}{|c|c|c|c|c|c|c|}
\hline Varieties & $\begin{array}{l}\text { Protein } \\
\left(\mathrm{g} \cdot \mathrm{kg}^{-1}\right)\end{array}$ & $\begin{array}{c}\text { Crude } \\
\text { fiber }\left(\mathrm{g} \cdot \mathrm{kg}^{-1}\right)\end{array}$ & $\begin{array}{l}\text { Vitamin C } \\
\left(\mathrm{mg} \cdot \mathrm{kg}^{-1}\right)\end{array}$ & $\begin{array}{c}\text { Reducing } \\
\text { sugar }\left(\mathrm{g} \cdot \mathrm{kg}^{-1}\right)\end{array}$ & $\begin{array}{l}\text { Sucrose } \\
\left(\mathrm{g} \cdot \mathrm{kg}^{-1}\right)\end{array}$ & $\begin{array}{c}\text { Soluble solid } \\
\text { content }(\%)\end{array}$ \\
\hline 'Jianbao' pumpkin & $10.1 \pm 0.70 \mathrm{~b}$ & $6.0 \pm 0.46 \mathrm{~b}$ & $213.0 \pm 7.00 \mathrm{~b}$ & $24.0 \pm 1.73 \mathrm{a}$ & $5.3 \pm 0.89 b$ & $9.1 \pm 1.70 \mathrm{ab}$ \\
\hline 'Japanese Sweet Chestnut' kabocha & $8.0 \pm 0.46 \mathrm{c}$ & $6.5 \pm 0.30 b$ & $208.0 \pm 3.46 b$ & $13.0 \pm 2.65 \mathrm{c}$ & $3.6 \pm 0.79 b$ & $6.2 \pm 0.83 b$ \\
\hline 'Beibei' pumpkin & $11.3 \pm 0.35 \mathrm{a}$ & $8.0 \pm 0.36 \mathrm{a}$ & $303.0 \pm 3.61 \mathrm{a}$ & $20.0 \pm 1.00 \mathrm{~b}$ & $13.0 \pm 2.65 \mathrm{a}$ & $12.3 \pm 2.11 \mathrm{a}$ \\
\hline
\end{tabular}

Different letters within the same column indicate the difference was significant $(P<0.05)$.

0.05). The dry matter content was higher than that of 'Japanese Sweet Chestnut' kabocha and 'Beibei' pumpkin $(P<0.05)$. The results of the 2-year field yield trials in five sites showed that the yield of 'Jianbao' was significantly higher than that of 'Japanese Sweet Chestnut' kabocha and 'Beibei' pumpkin $(P<0.05)$ in open-field and greenhouse cultivation (Table 1).

Jianbao was cultivated in spring in Fujian and planted from mid-February to early March; autumn cultivation was planted from early July to early August. In greenhouse cultivation, 10,500-12,000 plants per hectare were planted, and 9000-10,500 plants per hectare were planted in open-field, A-frame cultivation. Attention was paid to the prevention and treatment of powdery mildew.

\section{Quality Determination}

In the middle of April 2014, fresh and ripe pumpkins were collected, with 6 fruits from each variety. The fruits were first cleaned in distilled water and then the skin and seeds were removed. Each fruit was cut into 12 pieces and 4 were selected, giving a total of 24 pieces. The pieces were cut into $3-\mathrm{mm} \times 3$ $\mathrm{cm}$ strips and mixed evenly together. Fifty gram of pulp was accurately weighed, $50 \mathrm{~mL}$ of $2 \%$ oxalic acid solution was added, and the mixture was then homogenized using a highspeed tissue grinder for the determination of vitamin $\mathrm{C}$ content. Another $50 \mathrm{~g}$ of pulp was accurately weighed, $50 \mathrm{~mL}$ of pure water was added, and the mixture was then homogenized using a homogenizer for the determination of protein, reducing sugar, and sucrose contents. Three hundred gram of pulp was weighed, dried, and ground for the determination of cellulose content. Each sample was performed in triplicate. The protein content was determined using the GB/T 5009.5-2010 National Food Safety Standards-Determination of Protein Content in Food (Kjeldahl method, Ministry of Health of the People's Republic of China, 2010). In total, $10 \mathrm{~mL}$ of pulp juice was submersed in $20 \mathrm{~mL} \mathrm{H}_{2} \mathrm{SO}_{4}(1.84 \mathrm{~g} / \mathrm{L})$ combined with $0.20 \mathrm{~g} \mathrm{CuSO}_{4}$ and $6.00 \mathrm{~g}$ $\mathrm{K}_{2} \mathrm{SO}_{4}$ in a Kjeldahl bottle. The sample was digested at 300 to $400{ }^{\circ} \mathrm{C}$ for $1.5 \mathrm{~h}$ or more until the light blue color became transparent and was left boiling for another $0.5-1 \mathrm{~h}$. The sample was allowed to cool to room temperature and titrated with an indicator (methyl red or methylene blue) until the sample color changed from purple to gray. Total Kjeldahl nitrogen content was converted into total protein content by multiplying with the empirical coefficient of 6.25 . By using the GB/T 5009.10-2003 Determination of Crude Fiber in Vegetable Food (Ministry of Health of the
People's Republic of China, 2003), we determined the cellulose content. Dry pulp (5 g) was transferred to a conical flask to which $1.25 \%$ boiled $\mathrm{H}_{2} \mathrm{SO}_{4}$ was added. The sample was heated for $30 \mathrm{~min}$ and filtered with linen, and the residue was washed and transferred to a conical flask. Then, $1.25 \%$ boiled $\mathrm{NaOH}$ was added to the flask after which the insoluble residue was separated on a filter and washed. After drying and weighing, the loss of mass was analyzed via incineration. Reducing sugar was determined based on the GB/T 5009.7-2008 Determination of Reducing Sugar in Food (First Method: Direct Titration Method, Ministry of Health of the People's Republic of China, 2008a). Pulp juice $(10 \mathrm{~mL})$ was diluted to $200 \mathrm{~mL}$ with deionized water and incubated in a water bath for $1 \mathrm{~h}$ at $45^{\circ} \mathrm{C}$. The supernatant was transferred to a conical flask and $5 \mathrm{~mL}$ of lead acetate solution $(21.9 \%, \mathrm{w} / \mathrm{v})$ was slowly added. The mixture was used as titration solution A. Thereafter, $5 \mathrm{~mL}$ solution B $(0.15 \%$ copper (II) sulfate, $\mathrm{w} / \mathrm{v}$, and $0.005 \%$ methylene blue, w/v) and $5 \mathrm{~mL}$ solution $\mathrm{C}$ $(5.00 \%$ potassium sodium tartrate, $\mathrm{w} / \mathrm{v} ; 7.5 \%$ $\mathrm{NaOH}, \mathrm{w} / \mathrm{v}$; and $0.4 \%$ potassium ferrocyanide, $w / v)$ were added to the conical flask. After adding $10 \mathrm{~mL}$ of deionized water and 2 glass beads, the mixture was boiled for $2 \mathrm{~min}$. The solution was titrated with solution A until the blue color faded. Glucose was used to establish the standard curve to calculate the reducing sugar content in the pumpkins. Sucrose content was determined according to the GB/T 5009.8-2008 Determination of Sucrose in Food (First Method: Acid Hydrolysis Method; Ministry of Health of the People's Republic of China, 2003). Ten milliliters pulp juice was diluted to $30 \mathrm{~mL}$ with deionized water and $10 \mathrm{~mL}$ of copper sulfate solution $(7.0 \%, \mathrm{w} / \mathrm{v})$, and $4 \mathrm{~mL}$ of sodium hydroxide solution $(0.4 \%, \mathrm{w} / \mathrm{v})$ were added. After vortexing, the mixture stood for $30 \mathrm{~min}$ and then strained. Three milliliters of filtered liquid was transferred to a $10-\mathrm{mL}$ volumetric bottle for volumetric determination with acetonitrile. The sample was filtered with a $0.45-\mu \mathrm{m}$ filter and the filtrate was transferred to amber vials for highperformance liquid chromatography analysis under the following conditions: chromatographic column of $4.6 \mathrm{~mm} \times 250 \mathrm{~mm}, 5 \mu \mathrm{m}$; oven temperature at $25^{\circ} \mathrm{C}$; parallax detector pool temperature of $40^{\circ} \mathrm{C}$; the mobile phase with acetonitrile $(75 \%, \mathrm{w} / \mathrm{v})$; and a flow rate of $1 \mathrm{~mL} / \mathrm{min}$. The content of vitamin $\mathrm{C}$ was determined according to the GB/T 61951986 Determination of Vitamin C Content in Fruits and Vegetables (Ministry of Health of the People's Republic of China, 1986). The procedure was as follows: $100 \mathrm{~g}$ of fresh weight of pulp was extracted with $100 \mathrm{~mL}$ of leaching solution $(2.0 \%$ metaphosphoric acid, w/v, and $2.0 \%$ oxalic acid, w/v); after vortexing, $40 \mathrm{~g}$ of samples were diluted to $100 \mathrm{~mL}$ with the leaching solution and then the samples were filtered with filter paper. Ten milliliter of the filtrate was pipetted into a $50-\mathrm{mL}$ conical flask and titration was performed with calibrated 2,6-dichloropyridinol solution $(1 \mathrm{mg} / \mathrm{mL})$ until the solution was pink for $15 \mathrm{~s}$ without fading. Soluble solids content (SSC) was determined by a hand-held refractometer.

The protein content of 'Jianbao' was higher than that of 'Japanese Sweet Chestnut' kabocha but lower than that of 'Beibei' pumpkin $(P<0.05)$; the crude fiber and vitamin $\mathrm{C}$ contents in 'Jianbao' had no significant differences as that in 'Japanese Sweet Chestnut' kabocha but significantly lower than that in 'Beibei' pumpkin $(P<0.05)$. Compared with 'Japanese Sweet Chestnut' kabocha and 'Beibei' pumpkin, 'Jianbao' had the highest reducing sugar content, but sucrose content was significantly lower than that of 'Beibei' pumpkin $(P<0.05)$. The SSC in 'Jianbao' pumpkin was the same as that in 'Beibei' and 'Japanese Sweet Chestnut' kabocha, but the SSC in 'Beibei' was significantly higher than that in 'Japanese Sweet Chestnut' kabocha $(P<0.05)$ (Table 2).

\section{Availability}

'Jianbao' seeds can be obtained from Fujian Agricultural Science and Agricultural Development Co., Ltd., first Floor, Fujian Academy of Agricultural Sciences, No. 188 Hualin Road, Huada Street, Gulou District, Fuzhou City 350003, China.

\section{Literature Cited}

Chu, P., C. Xiang, C. Zhang, and C. Liu. 2007. Genetic diversity of Cucurbita moschata genotypes revealed by RAPD markers and agronomic traits. J. Nucl. Agr. Sci. 21:441-446.

Fang, Z. 2001. Research method for plant pathology. 3rd ed. China Agriculture Press, Beijing, China.

Jia, C., H. Li, G. Qu, and F. Zhang. 2007. A new pumpkin F1 hybrid 'Duanmanjinglüli'. China Veg. 5:31-33.

Li, X. and D. Zhu. 2005. Description standard and data standard of Cucumber Germplasm Resources. China Agricultural Press, Beijing, China

Liu, Y., D. Lin, X. Sun, and C. Wang. 2008 Advances on the Cucurbit industry and Cucurbit science and technology in China. Chinese Cucurbits Veg. 6:4-9.

Ministry of Health of the People's Republic of China. 1986. GB/T 6195-1986: National food safety standard-Determination of Vitamin C Content in Fruits and Vegetables (in Chinese).

Ministry of Health of the People's Republic of China. 2003. GB/T 5009.10-2003: National 
food safety standard-Determination of Crude Fiber in Vegetable Food (in Chinese).

Ministry of Health of the People's Republic of China. 2008a. GB/T 5009.7-2008: National food safety standard-Determination of Reducing Sugar in Food (in Chinese).

Ministry of Health of the People's Republic of China. 2008b. GB/T 5009.8-2008: National food safety standard-Determination of Sucrose in Food (in Chinese).
Ministry of Health of the People's Republic of China. 2010. GB/T 5009.5-2010: National food safety standard-Determination of Protein Content in Foods-Kjeldahl method (in Chinese).

Semeniuk, P., H.E. Moline, and J.A. Abbott. 1986 A comparison of the effects of ABA and an antitranspirant on chilling injury of coleus, cucumbers, and dieffenbachia. J. Amer. Soc. Hort. Sci. 11:866-868.
Wang, M. 2002. Genus Cucurbita-The most diversity. J. China Watermelon Melon. 3:42-45.

Yang, H., Y. Li, C. Wang, G. Liang, J. Wang, and X. Liu. 2016. Correlation and regression analysis of taste evaluation and nutrient components in squash. Zhongguo Shucai 11:25-32

Zhao, Y., X. Li, and J. Zhou. 2009. Worldwide production and diversity characteristics of Cucurbita species. J. Inner Mongolia Agr. Uni. 4:112-114. 